\title{
BEILSTEIN ARCHIVES
}

This open access document is published as a preprint in the Beilstein Archives with doi: 10.3762/bxiv.2019.109.v1 and is considered to be an early communication for feedback before peer review. Before citing this document, please check if a final, peer-reviewed version has been published in the Beilstein Journal of Nanotechnology.

This document is not formatted, has not undergone copyediting or typesetting, and may contain errors, unsubstantiated scientific claims or preliminary data.

Preprint Title Binary Solid Lipid Nanosuspension Containing Cefixime: Preparation, Characterization and Comparative In-vivo Evaluation

Authors Mahwish Kamran, Mir Azam Khan, Maqsood ur Rehman, Muhammad Shafique, Abdullah Khan and Sajjad Ahmad

Publication Date 26 Sep 2019

Article Type Full Research Paper

ORCID ${ }^{\circledR}$ iDs Mahwish Kamran - https://orcid.org/0000-0002-8527-5921; Mir Azam Khan - https://orcid.org/0000-0002-6685-6472; Maqsood ur Rehman - https://orcid.org/0000-0002-3969-9555; Abdullah Khan https://orcid.org/0000-0002-3698-0616; Sajjad Ahmad https://orcid.org/0000-0002-0932-1922 


\section{Binary Solid Lipid Nanosuspension Containing Cefixime: Preparation, Characterization and Comparative In-vivo Evaluation}

Mahwish Kamran ${ }^{1}$, Mir Azam Khan*1, Maqsood ur Rehman ${ }^{1}$, Muhammad Shafique ${ }^{1}$, Abdullah Khan ${ }^{1}$ and Sajjad Ahmad²

${ }^{1}$ Department of Pharmacy, University of Malakand, Chakdara; Dir (L)-18800 Khyber Pakhtunkhwa, Pakistan

${ }^{2}$ Department of Pharmacy, Faculty of Life Sciences, Sarhad University of Science and Information Technology, Peshawar, Pakistan

* Corresponding author

Email: Dr. Mir Azam Khan- Professor \& Dean Faculty of Biological Sciences, University of Malakand-Pakistan mirazam786@yahoo.com 


\section{Abstract}

Current study focused on resolution of poor oral bioavailability issues of cefixime through fabrication of its freeze dried binary solid lipid nano particles (SLNs). The nano formulation fabricated via hot melt encapsulation (HME) method was optimized using numerous formulation variables. Optimized nano formulation (CFX-4) showed particle size $206.6 \pm 2.3 \mathrm{~nm}$, polydispersity index (PDI) $0.271 \pm 0.03$, zeta potential (ZP) $-30.7 \pm 3.1 \mathrm{mV}$, encapsulation efficiency (EE\%) $88.2 \pm 2.3 \%$ along with drug loading capacity (DLC\%) $4.83 \pm 0.16 \%$. Micrograph of scanning electron microscopy (SEM) represented spherical shaped particles. Reduction in drug's crystalline nature was acknowledged through differential scanning calorimetry (DSC) and x-ray powder diffraction (P-XRD) analysis. Drug-excepient compatibility was established through fourier transform infrared spectroscopic (FT-IR) analysis. During in-vitro studies; sustained drug release was favored by increased drug payload. Stability studies exposed that refrigerated temperature imparts maximum stability to binary SLNs. Invivo pharmacokinetic studies revealed the desired enhancement in oral bioavailability compared to the marketed product $\left(\right.$ Cefiget $\left.^{\circledR}\right)$. Presented investigations established the dominance of binary SLNs for improvement of oral bioavailability with sustained drug release characteristics. Based on the reported outcomes, binary SLNs can be employed as an advanced drug delivery system for other hydrophobic drugs.

\section{Keywords}

Hot melt encapsulation; binary solid lipid nano particles; bioavailability; in-vitro; invivo study. 


\section{Introduction}

Poor oral bioavailability of hydrophobic active pharmaceutical ingredients (APIs) is the foremost confront in drug deliverance [1, 2]. Poor dissolution rate limited bioavailability of different drugs is a stumbling block in their commercialization. Previously various techniques like solid dispersion, salt formation and complexation etc were employed to address low bioavailability issues of hydrophobic drugs [3-5]. Unfortunately, unavoidable disadvantages like limited physical stability, presence of remaining organic solvents, expulsion of drug during storage, low drug loading capacity as well as polymeric cyto toxicity were linked with these colloidal carrier systems [6]. These disadvantages necessitated the urge for development of advanced drug delivery systems.

Nano particulate drug delivery system like solid lipid nano particles (SLNs) are extensively employed for delivery of hydrophobic drugs [7]. Oral bioavailability enhancement of hydrophobic drugs via nano technology is favored by two well known mechanisms including; increase in surface area of the particles as well as reduction in their crystallinity [8, 9]. Additionally, the use of lipids in SLNs enhances drug absorption by improving gastrointestinal permeability, augmenting lymphatic transport and delaying gastric emptying rate [10]. Further, advancement in SLNs leads to the development of binary SLNs formulated from the blend of solid and liquid lipid. Binary SLNs offers improved physicochemical properties and enhanced encapsulation efficiency [11]. Furthermore, incorporation of liquid lipid in the solid lipid also prolongs drug release from binary SLNs [12].

Cefixime (cephalosporin antibiotic) is widely utilized in the management of respiratory and urinary tract infections, gonococcal urethritis and acute otitis media [13]. Cefixime (CFX) exerts antibacterial action by binding to $\beta$-lactam binding proteins 
and interfering with bacterial peptidoglycan cell wall synthesis [14]. Its oral bioavailability is approximately $22-54 \%$ [15]. The chief tribulation with this drug is poor aqueous solubility and erratic dissolution in biological fluids within gastro intestinal tract (GIT) resulting in low oral bioavailability [16]. In designing a drug formulation poor aqueous solubility of drugs like CFX is a foremost barrier resulting in poor systemic drug levels [17]. Therefore, the aim of present research work is the development of binary SLNs to improve solubility and bioavailability of CFX for its successful oral delivery.

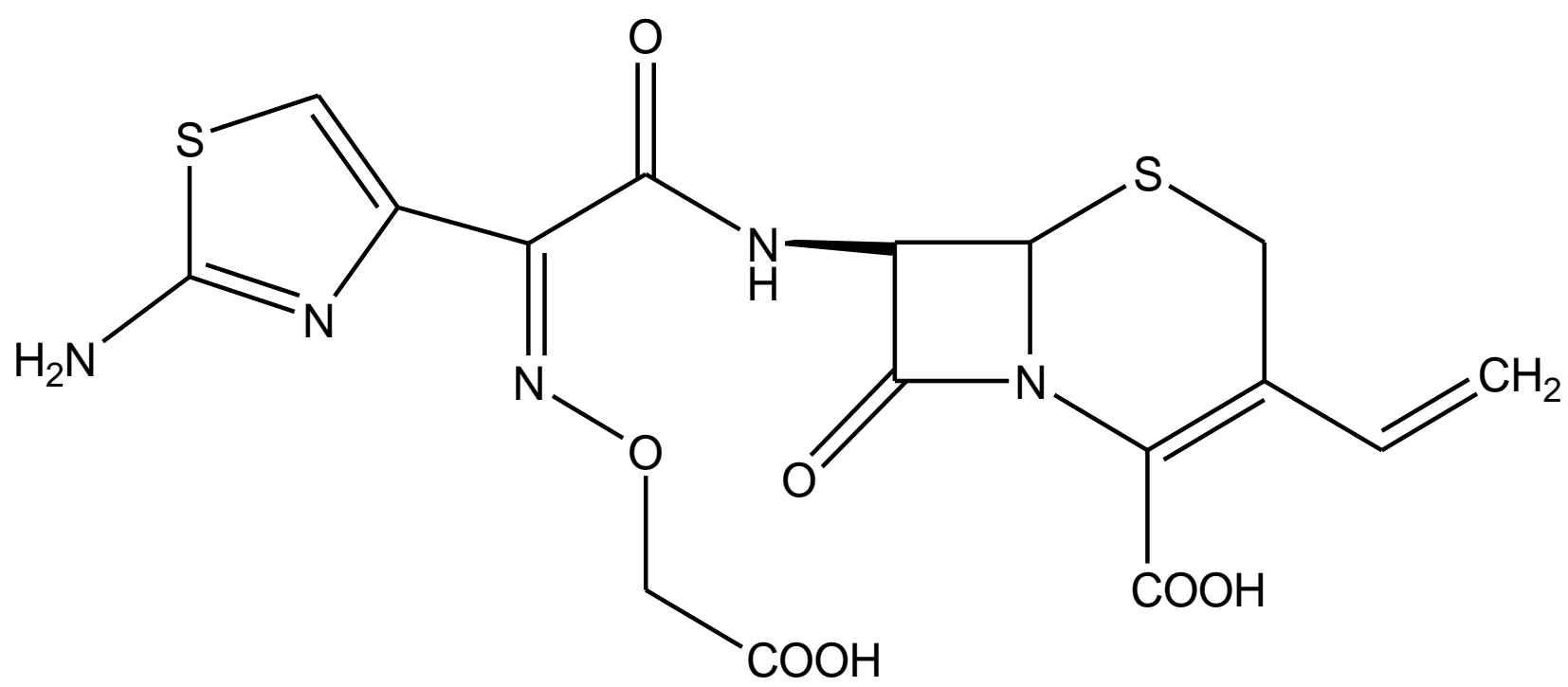

Figure 1: Chemical structure of Cefixime.

\section{Experimental}

\section{Materials}

Cefixime was supplied as kind endowment by Alliance Pharma (Pvt) Ltd, PeshawarPakistan. Stearic acid (SA), polyethylene glycol (PEG-400) and Tween-80 were acquired from Acros Organics Thermo Fisher Scientific, New Jersey-USA. Oleic acid (O.A) was obtained from E.Merck, D-6100 Darmstadt and F.R. Germany. Dialysis bags were provided by Spectrum laboratory Canada. Deionized (DI) water was 
prepared through Millipore ultra-pure water purification system (Milford-USA). All reagents and chemicals utilized in the study were of analytical grade.

\section{Method}

\section{Production of unloaded binary SLNs}

Five different unloaded nano formulations (UBS-1 to UBS-5) were prepared by HME technique. Optimization was conducted through different concentration of surfactant and cosurfactant along with stirring time (Table 1) [18]. Solid lipid (SA) was heated 10 ${ }^{\circ} \mathrm{C}$ beyond its melting point, with subsequent addition of liquid lipid (oleic acid) to prepare the lipid phase [19]. Similarly, aqueous phase was prepared by adding surfactant (Tween-80) and cosurfactant (PEG-400) in DI water and was heated till 79 ${ }^{\circ} \mathrm{C}$. Both phases were mixed under continued stirring and heating to form hot melt microemulsion. Further, heating was turned off while magnetic stirring was continued till room temperature to obtain desired nano-particles (suspension). The obtained blank binary SLNs dispersion was subjected to sonication with subsequent centrifugation for $10 \mathrm{~min}$ at $30,000 \mathrm{rpm}$ to conduct further characterization.

Table 1: Formulations of un-loaded binary SLNs.

\begin{tabular}{|c|c|c|c|c|c|c|c|c|}
\hline Sample & $\begin{array}{c}\text { S.A } A^{a} \\
\text { (g) }\end{array}$ & $\begin{array}{l}\text { O. } A^{b} \\
(\mathrm{ml})\end{array}$ & $\begin{array}{c}\text { Tween- } \\
80 \\
(\mathrm{ml})\end{array}$ & $\begin{array}{c}\text { PEG }^{\mathrm{c}} \\
\text { (g) }\end{array}$ & $\begin{array}{c}\text { Stirring- } \\
\text { time } \\
\text { (min) }\end{array}$ & $\begin{array}{l}\text { Soni- } \\
\text { time } \\
(\min )\end{array}$ & $\begin{array}{l}\text { Paticle } \\
\text { Size } \\
(\mathrm{nm})\end{array}$ & PDI \\
\hline UBS-1 & 2.00 & 0.2 & 1 & 0 & 5 & 5 & $404.3 \pm 2.1$ & $0.405 \pm 0.005$ \\
\hline UBS-2 & 2.00 & 0.2 & 2 & 0 & 5 & 5 & $335.3 \pm 2.3$ & $0.543 \pm 0.002$ \\
\hline UBS-3 & 2.00 & 0.2 & 1.8 & 0.2 & 5 & 5 & $251.1 \pm 2.5$ & $0.511 \pm 0.003$ \\
\hline UBS-4 & 2.00 & 0.2 & 1.6 & 0.4 & 5 & 5 & $237.3 \pm 2.7$ & $0.382 \pm 0.002$ \\
\hline UBS-5 & 2.00 & 0.2 & 1.6 & 0.4 & 10 & 5 & $223.7 \pm 2.3$ & $0.322 \pm 0.004$ \\
\hline
\end{tabular}

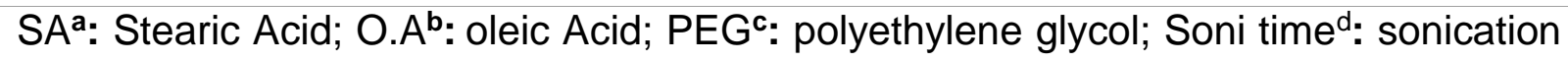
time. 


\section{Production of CFX-loaded binary SLNs}

After optimization, the best formulation (UBS-5) was selected for drug loading. Depending upon lipid to drug ratio various drug loaded formulations CFX-1 (100 mg), CFX-2 (150 mg), CFX-3 (200 mg), CFX-4 (250 mg) and CFX-5 (300 mg) were prepared. During this process drug was added to the mixture of melted lipid followed by vortexing. Remaining process pursued was the same as followed for production of unloaded binary SLNs.

\section{Determination of encapsulation efficiency and drug loading capacity}

After centrifugation, fraction of unentrapped drug in the supernatant of nano formulations was calculated to determine encapsulation efficiency (EE\%) and drug loading capacity (DLC\%). Samples of supernatant were analyzed for CFX by UV spectrophotometer (UV-1800 240 V Shimadzu, Japan) at 283 nm [20]. EE\% and DLC\% were determined using the following set of equations.

$$
\begin{aligned}
\text { EE\% } & =\frac{\text { Total drug content used }- \text { Amount of unloaded drug }}{\text { Total drug content used }} \times 100 \\
\text { DLC } \% & =\frac{\text { Tmotal drug content used }+ \text { Amount of excipients }}{\text { Total }} \times 100
\end{aligned}
$$

\section{Freeze drying}

Lyophillization was carried out using freeze dryer (ScanVac, cool safe 4-15L) for optimized nano formulation (CFX-4). Prior to freeze drying glucose solution (10\%) was used as a cryoprotectant [21]. Optimized nano formulation was refrigerated at 20 ${ }^{\circ} \mathrm{C}$ overnight followed by lyophillization $\left(-75^{\circ} \mathrm{C}\right)$ for $48 \mathrm{hrs}$ [22]. 


\section{Zeta sizer analysis}

Measurement of particle size, PDI and ZP is an efficient mean of product characterization. Zeta sizer (Malvern Zeta-sizer nano ZSP, Instrument UK) at scattering angle $90^{\circ}$ and $25{ }^{\circ} \mathrm{C}$ temperature was used to analyze the prepared nano formulations [19].

\section{Surface morphological studies (SEM)}

The micrographs of scanning electron microscope (FEI, Nova Nano SEM 450) were obtained to evaluate morphological patterns of CFX binary SLNs at an accelerating voltage of $5 \mathrm{kV}$ [23].

\section{Thermal analysis}

Thermal behavior of pure CFX, lipid, physical mixture as well as processed nano formulation (CFX-4) was assessed through differential scanning calorimeter (Perkin Elmer, Diamond Series DSC-USA). During DSC analysis, sample (3-5 mg) was heated between $40-300{ }^{\circ} \mathrm{C}$ in aluminum pans under nitrogen purge at scanning rate $10^{\circ} \mathrm{C} / \min [25]$.

\section{Powder X-ray diffraction (P-XRD)}

P-XRD analysis was conducted for pure CFX and prepared nano formulation (CFX-4) utilizing Bruker, D2 Phaser Diffractrometer, to evaluate reduction in crystalline nature of optimized nano formulation (CFX-4). Measurements were made by exposing the samples to CuKa radiation, tube current $(40 \mathrm{kV} \times 40 \mathrm{~mA})$, diffraction angle $(2 \theta)$ in the scanning range $\left(2 \theta=5^{\circ}-80^{\circ}\right)$, step size: $0.050^{\circ}$, step time: $1 \mathrm{~s}$, receiving slit: $0.2 \mathrm{~mm}$ and scattering slit: $1^{\circ}[26]$.

\section{Drug excepient interaction}

Drug-excepient interaction was studied by recording spectra of pure CFX, SA, physical mixture, $\mathrm{OA}$ and optimized nano formulation (CFX-4) using Fourier transform infrared (FT-IR) spectrophotometer (Bruker Alpha-P instrument). Analysis 
was conducted in the range of $4000-500 \mathrm{~cm}^{-1}$ [24]. Significant interactions were evaluated by comparing spectra of pure CFX with prepared nano formulation (CFX$4)$.

\section{Long term stability studies}

During stability studies, the optimized nano-formulation (CFX-4) was placed in two glass tubes and stored at refrigerated $\left(4 \pm 2{ }^{\circ} \mathrm{C}\right)$ and room temperature $\left(25 \pm 3{ }^{\circ} \mathrm{C}\right)$. Samples were withdrawn after $1^{\text {th }}, 15^{\text {th }}, 30^{\text {th }}, 60^{\text {th }}$ and $90^{\text {th }}$ day of storage and were analyzed to evaluate changes in particle size and PDI [10]. The obtained data was put forward to two-tailed t-test trial with $p$-value less than 0.05 for statistical analysis.

\section{In-vitro dissolution study}

Drug release behavior of CFX nano formulations was studied through dialysis bag technique. Dialysis bags (MWCO: $14 \mathrm{KDa}$ ) filled with samples were placed in to dissolution apparatus (100 rpm) containing phosphate buffer $(300 \mathrm{ml}, \mathrm{pH} 7.4$,$) which$ was maintained at $37 \pm 2{ }^{\circ} \mathrm{C}$ [27]. Samples were taken at regular time intervals (1-12 hrs) with replacement of dissolution medium for volume make up. Spectrophotometric analysis $(\lambda \max 287 \mathrm{~nm}$ ) of samples was conducted to evaluate percent drug release [28]. Drug release pattern and its release rate was studied by putting the data into specialized kinetic models [29].

\section{In-vivo studies}

The code of behavior for in-vivo pharmacokinetic studies was acknowledged by animal ethical committee, University of Malakand vide letter \# DREC/20190403/16. Rabbits weighing $2 \pm 0.2 \mathrm{Kg}$ were kept fasted for $12 \mathrm{hrs}$, with free access to water before dosage administration. Nano-formulation (CFX-4), $(1 \mathrm{~mL} / \mathrm{kg}$ nano suspension $=10 \mathrm{mg} \mathrm{CFX})$ and the marketed product $(10 \mathrm{mg} / \mathrm{kg})$ were orally administered to rabbits arranged in two groups. Blood samples withdrawn at regular time interval (0$24 \mathrm{hrs}$ ) were shifted to heparinized tubes. Samples were subjected to centrifugation 
to separate the plasma, and stored at $-20{ }^{\circ} \mathrm{C}$ till high performance liquid chromatographic (HPLC) analysis [30].

\section{HPLC studies}

HPLC analysis was performed for quantifying CFX in different plasma samples. Reversed phase column $\mathrm{C}_{8}$ (Altex Ultra sphere Octyl; $15 \mathrm{~cm}$ x $4.6 \mathrm{~mm}$ i.d, $5 \mu \mathrm{m}$ ) was used for analysis. Column was eluted with methanol $(12.5 \mathrm{mmol} / \mathrm{L})$ and monobasic sodium potassium buffer $(\mathrm{pH} 2.6,20: 80)$ as mobile phase. Sample (20 $\mu \mathrm{l})$ was injected at flow rate $2 \mathrm{~mL} / \mathrm{min}$, retention time $4.8 \mathrm{~min}$ and analyzed at $240 \mathrm{~nm}$ [15]. Area under curve $\left(\mathrm{AUC}_{0-24}\right)$, measured from the linear plot by applying trapezoidal rule was used as determinant of drug plasma concentration [31]. Peak plasma concentration $\left(\mathrm{C}_{\max }\right)$ as well as time to maximum concentration $\left(\mathrm{T}_{\max }\right)$ was estimated via individual plasma concentration versus time graphs. Relative bioavailability after $24 \mathrm{hrs}$ was determined by using the formula.

$$
F r=\frac{A \cup C-C F X-4^{0 \rightarrow 24}}{A \cup C-\text { Marketed broduct }}
$$

The obtained pharmacokinetic parameters for nano formulation (CFX-4) and the marketed product were statistically analyzed through ANOVA and t-test (Probability < 0.05)

\section{Results}

\section{Zeta sizer analysis}

Unloaded nano formulation (UBS-5) being optimized by different variables demonstrated particle size and PDI as $223.7 \pm 2.3 \mathrm{~nm}$ and $0.322 \pm 0.004$ respectively 
(Figure 2). Drug loaded formulation (CFX-4) showed particle size $206.6 \pm 2.3 \mathrm{~nm}$ along with PDI $0.271 \pm 0.03$ (Figure 3). Likewise, zeta potential was recorded as $-30.7 \pm 3.1$ $\mathrm{mV}$ (Figure 4).

\section{Zeta Size and PDI of Unloaded binary SLNs}

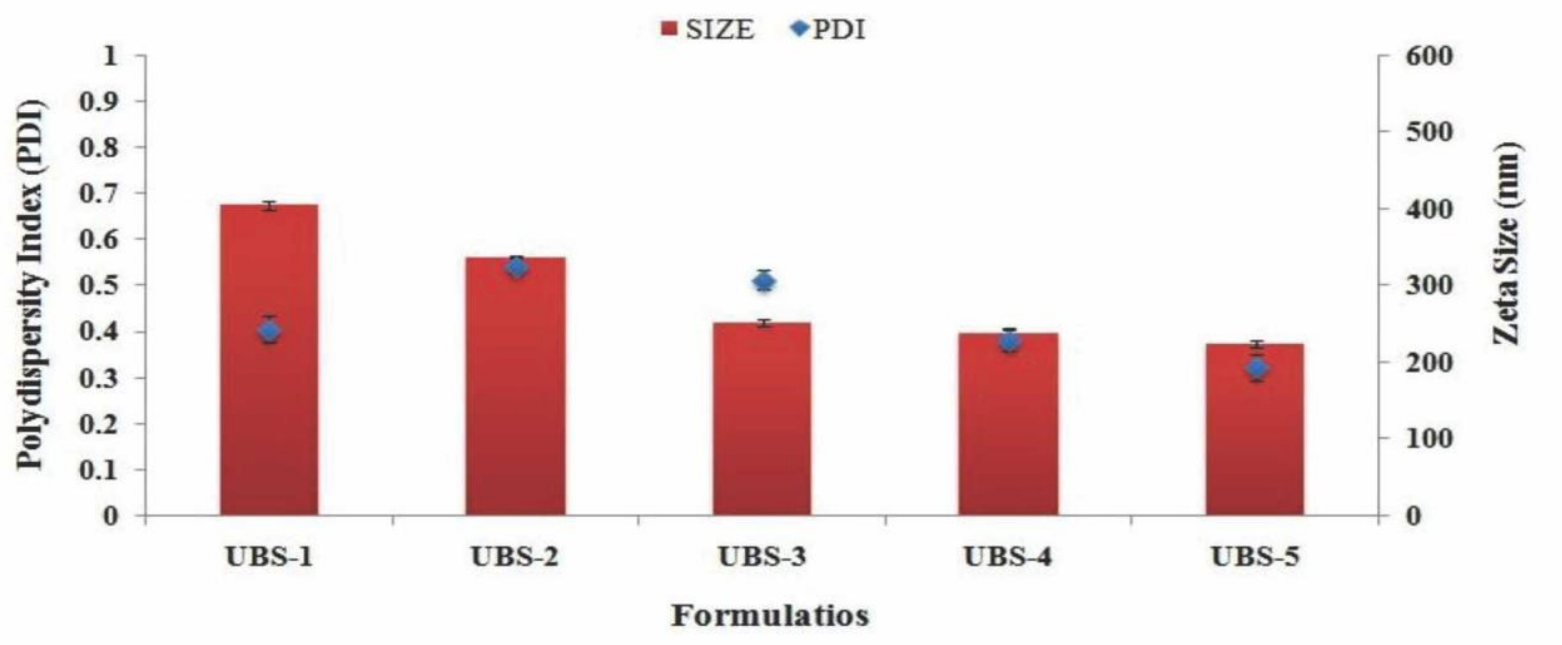

Figure 2: Size and PDI of Unloaded formulations.

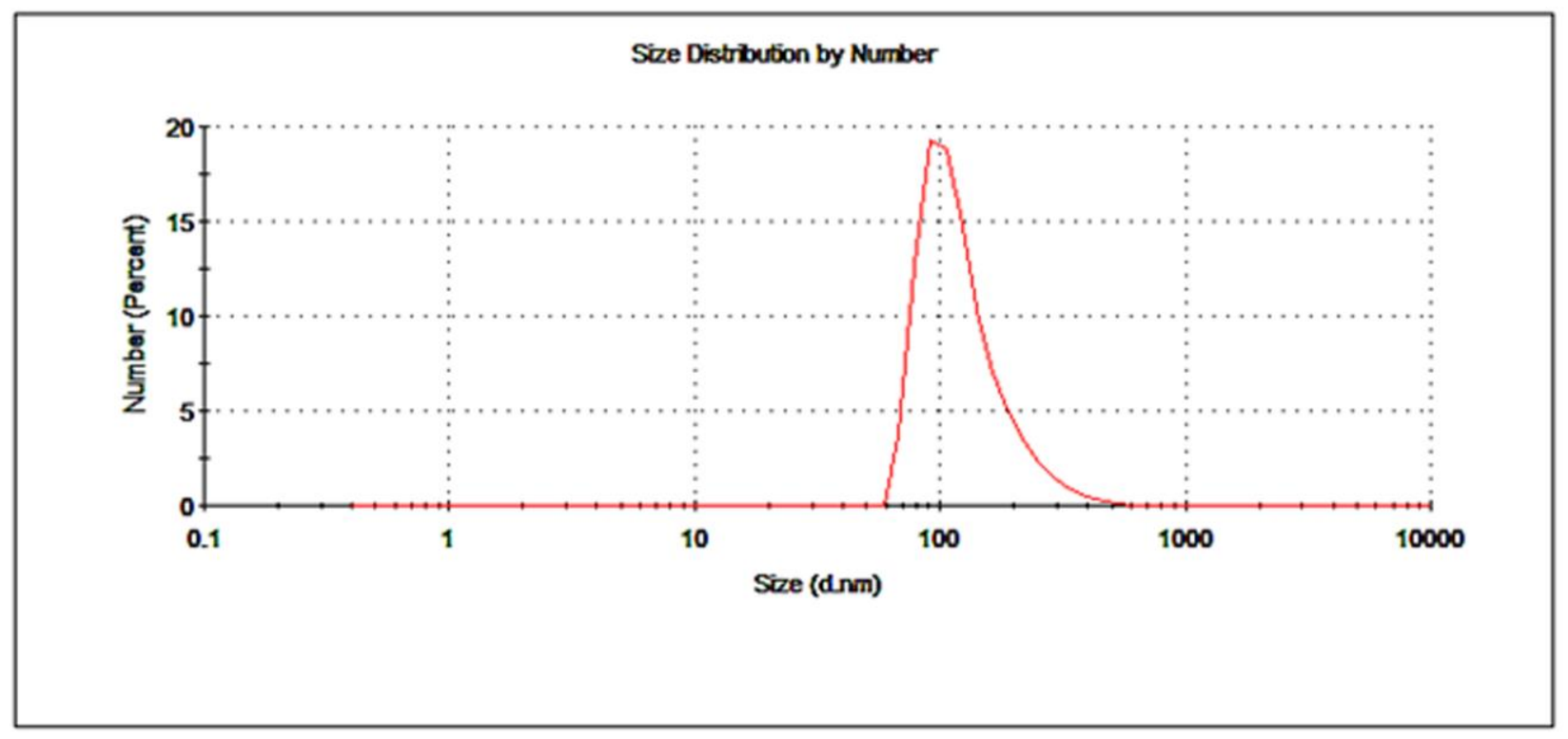

Figure 3: Particle size for optimized drug loaded formulation (CFX-4). 


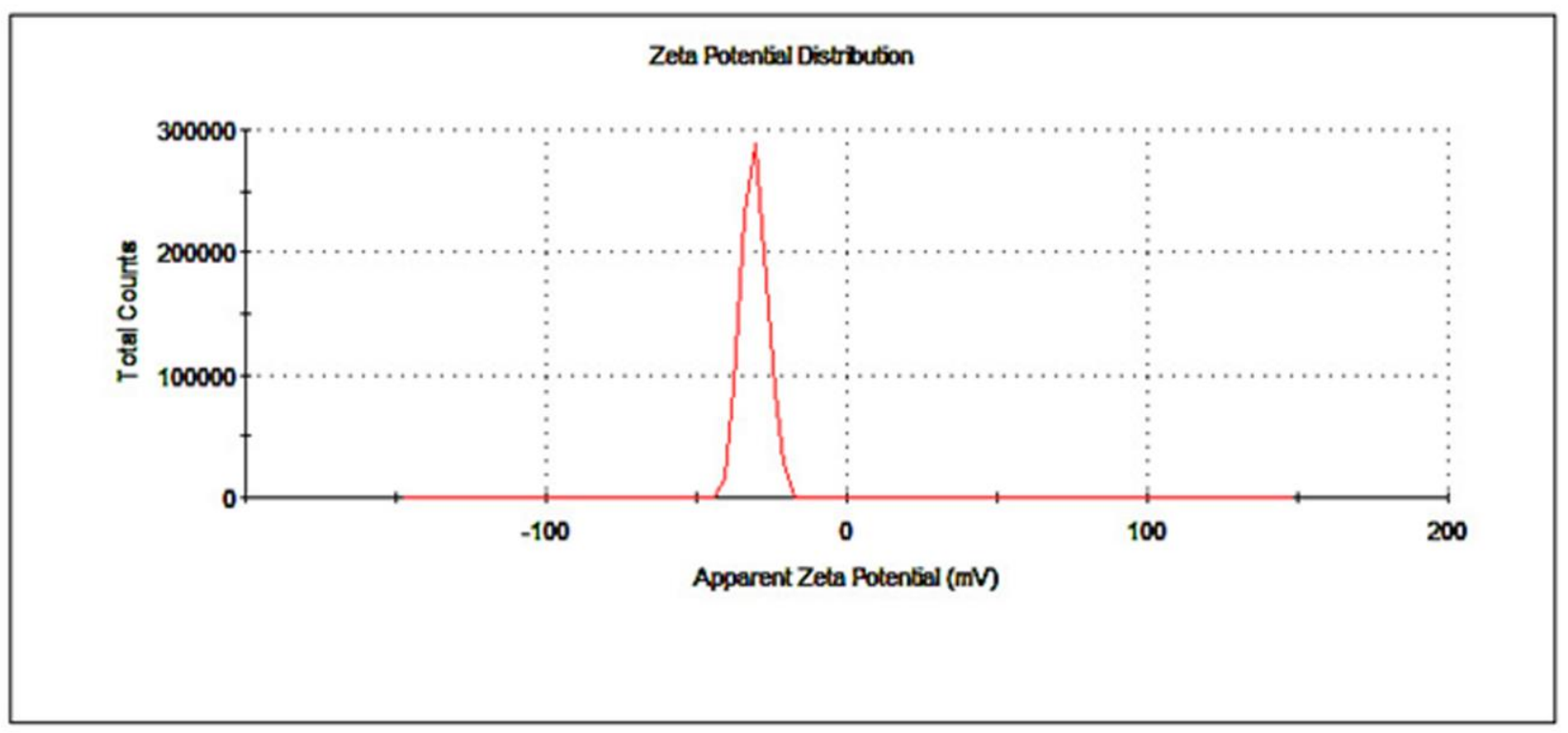

Figure 4: Zeta potential for optimized drug loaded formulation (CFX-4).

\section{Encapsulation efficiency and drug loading capacity}

Encapsulation efficiency (EE\%) as well as drug loading capacity (DLC\%) for CFX-1 was found to be $96.2 \pm 2.3 \%$ and $2.23 \pm 0.16 \%$ and for CFX-5 it was $76.1 \pm 2.5 \%$ and $5.26 \pm 0.16 \%$ respectively. Whereas, optimized nano formulation (CFX-4) reported EE\% $88.2 \pm 2.3 \%$ and DLC\% $4.83 \pm 0.16 \%$ (Figure 5).

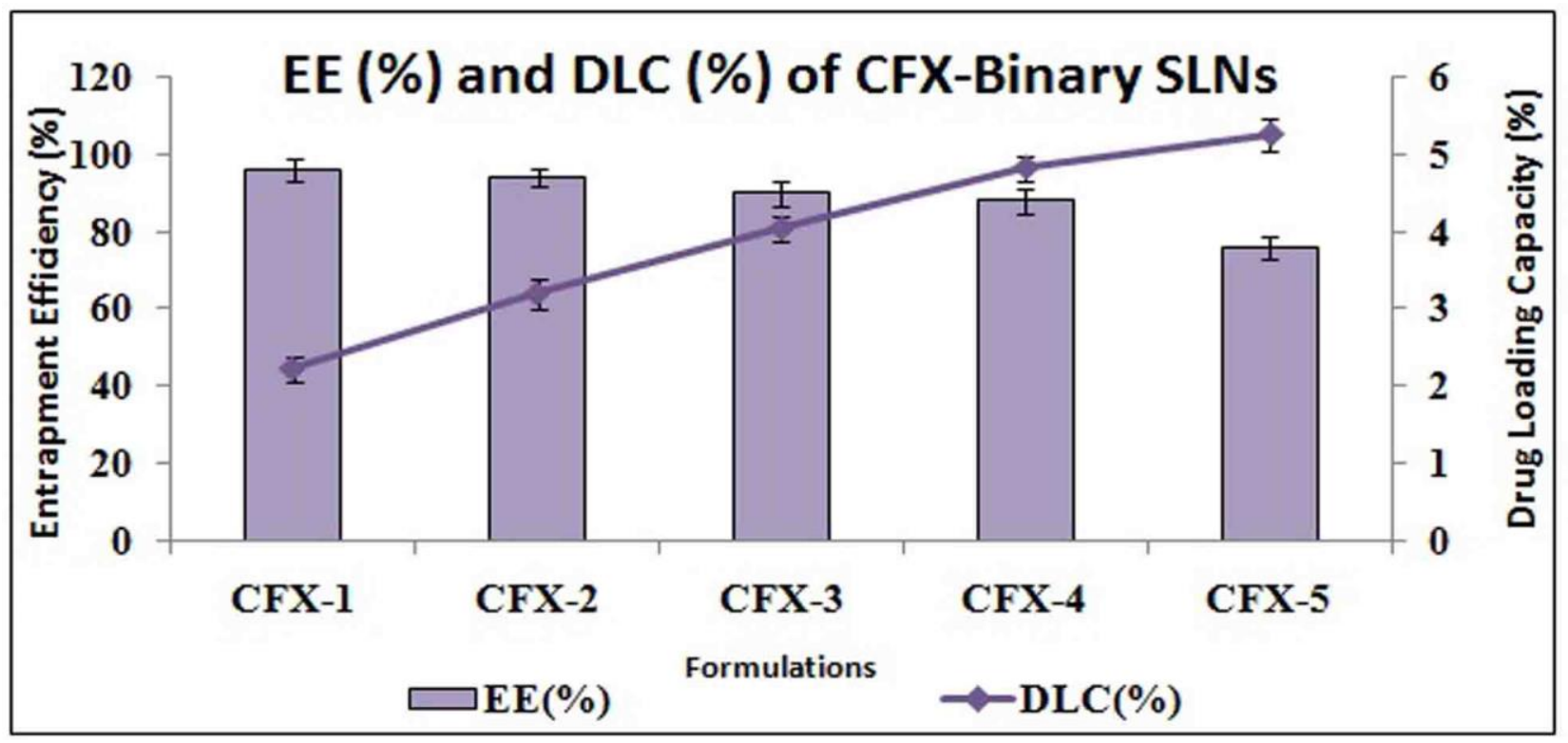

Figure 5: EE\% and DLC\% for different CFX- binary SLNs formulations. 


\section{Surface morphological studies (SEM)}

Optimized CFX nano formulation analyzed through SEM demonstrated identical, relatively spherical shaped and smooth surfaced particles (Figure 6).

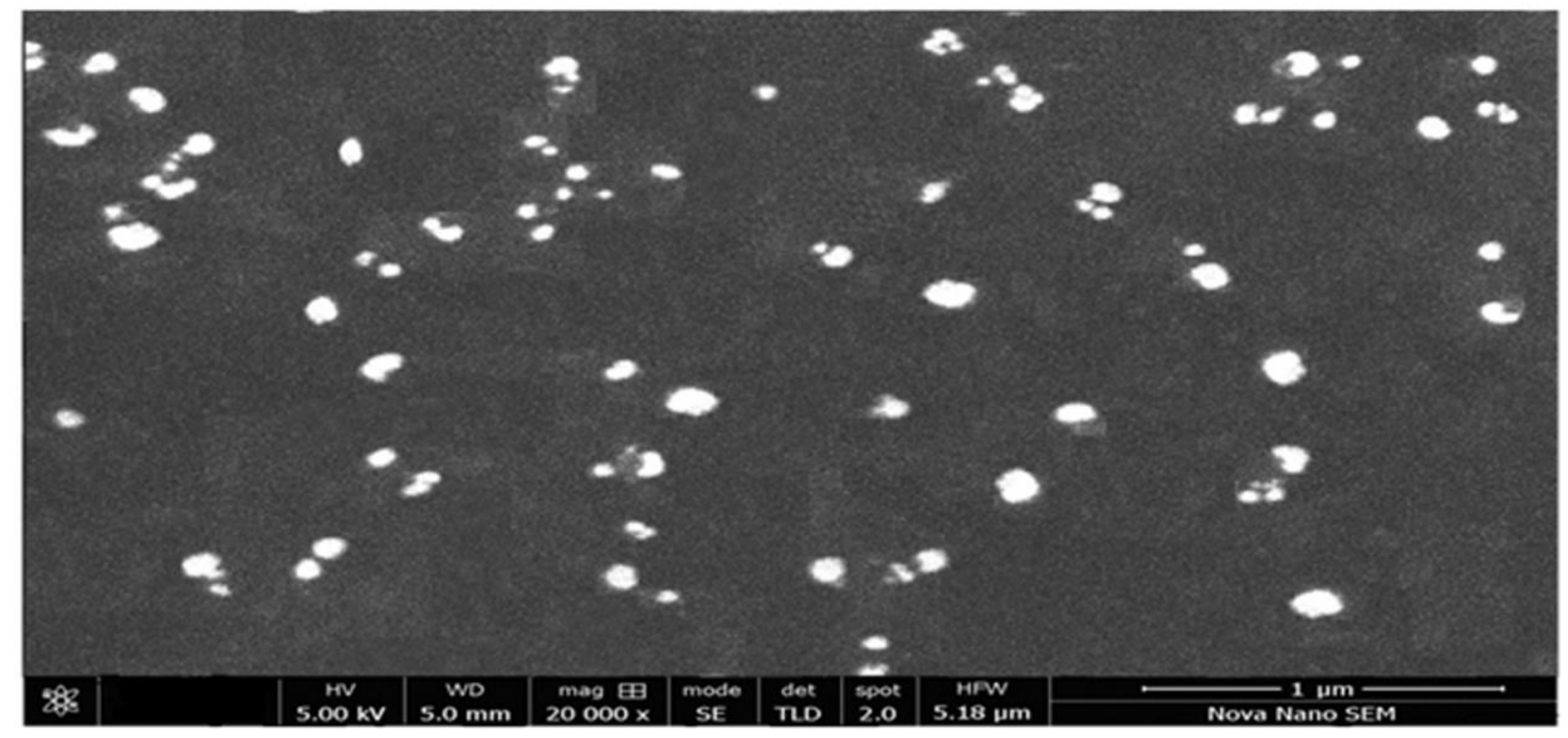

Figure 6: SEM micrograph for optimized nano formulation (CFX-4).

\section{Thermal analysis}

During analysis sharp endothermic peak appeared for pure CFX at $220^{\circ} \mathrm{C}$, while for processed nano formulation (CFX-4) it was slightly reduced and appeared at $215{ }^{\circ} \mathrm{C}$ (Figure 7). Whereas, for SA endothermic peak appeared at $69{ }^{\circ} \mathrm{C}$ and for physical mixture (CFX and SA) it was observed at $219.7^{\circ} \mathrm{C}$ and $68.8^{\circ} \mathrm{C}$ correspondingly. 


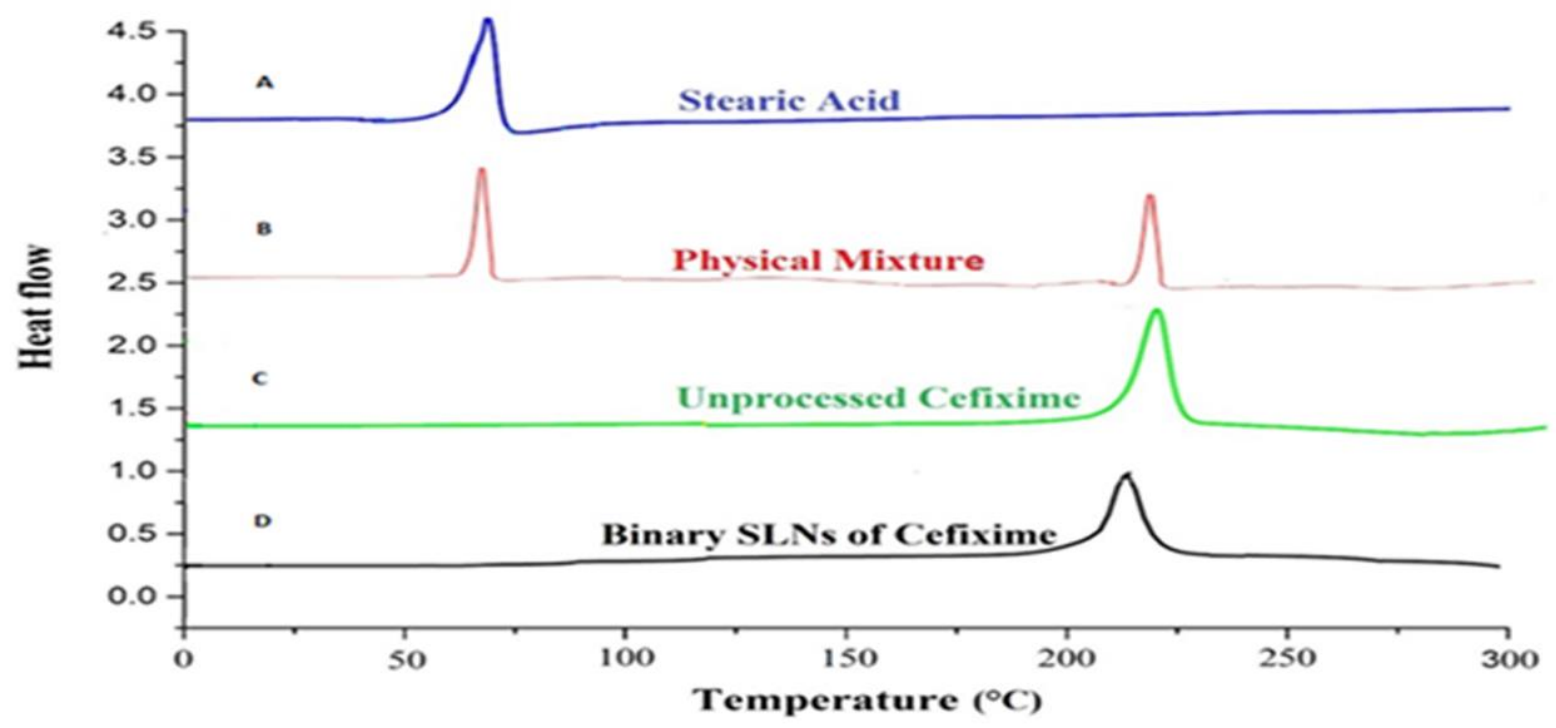

Figure 7: DSC scan of S.A (A), physical mixture (B), pure CFX (C), and processed

$$
\text { CFX (CFX-4) (D). }
$$

\section{Powder X-ray diffraction (P-XRD)}

P-XRD analysis was used to examine the changes in drug's crystallinity. Analysis of pure CFX revealed sequence of sharp peaks demonstrating crystalline form of CFX. Whereas, reduction in drug's crystalline state was confirmed through diffused peaks pattern observed for processed nano formulation (CFX-4) (Figure 8).

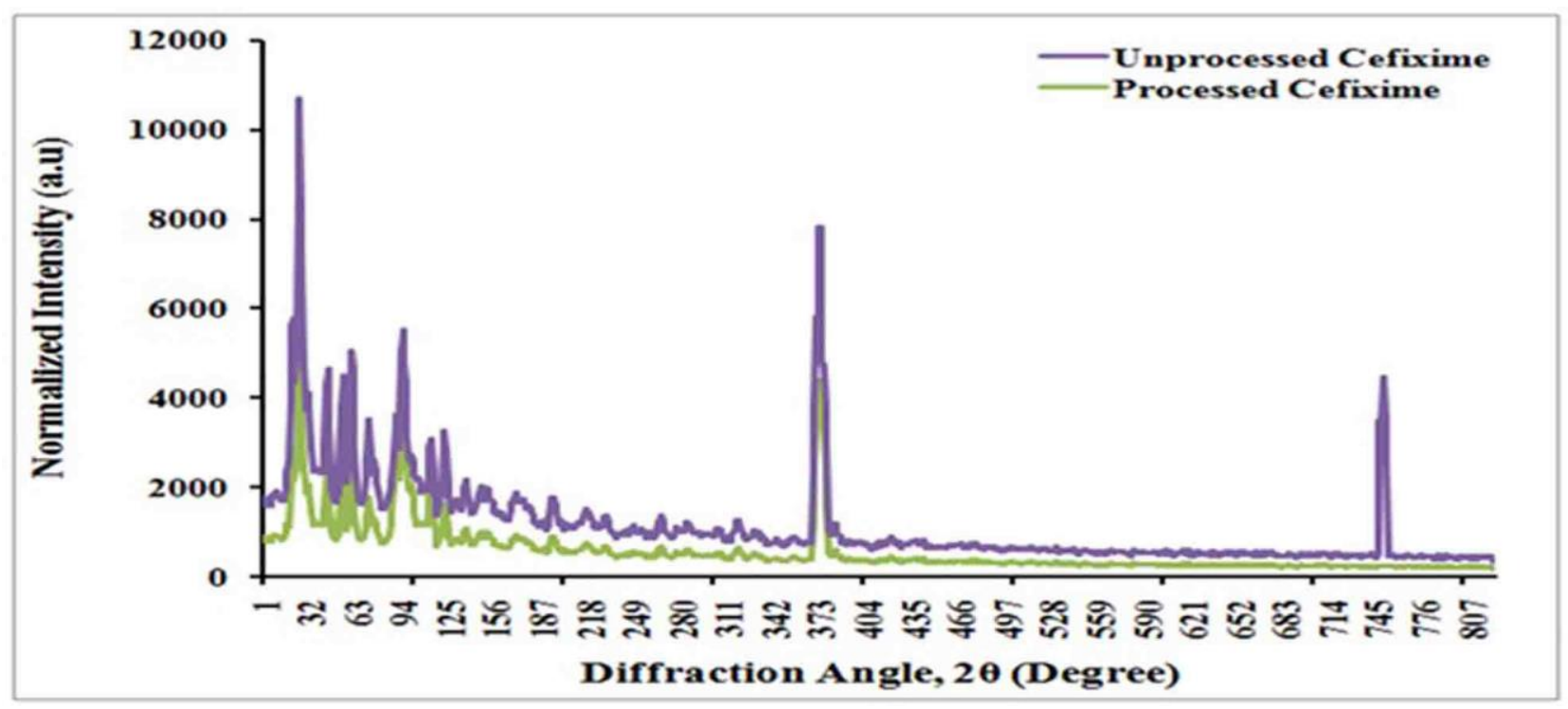

Figure 8: P-XRD graph for processed and un-processed CFX. 


\section{Drug excepient interaction}

Compatibility between the drug and formulation ingredients was evaluated through FT-IR analysis in the range of $500-4000 \mathrm{~cm}^{-1}$. Significant peaks were observed in FTIR spectra of pure CFX as well as processed nano formulation (CFX-4) at $3564 \mathrm{~cm}^{-1}$, $3293 \mathrm{~cm}^{-1}$ (N-H stretching), $1777 \mathrm{~cm}^{-1}$ (C-O and $\mathrm{COOH}$ stretching), $1677 \mathrm{~cm}^{-1}$ (C-O stretching, $\mathrm{CONH}), 1588 \mathrm{~cm}^{1}$ (stretching ring vibrations), $746 \mathrm{~cm}^{-1}$ (C-H bending). On analysis no significant peak shifting and loss of functional group was observed in both the spectras indicating drug-excepient compatibility (Figure 9).

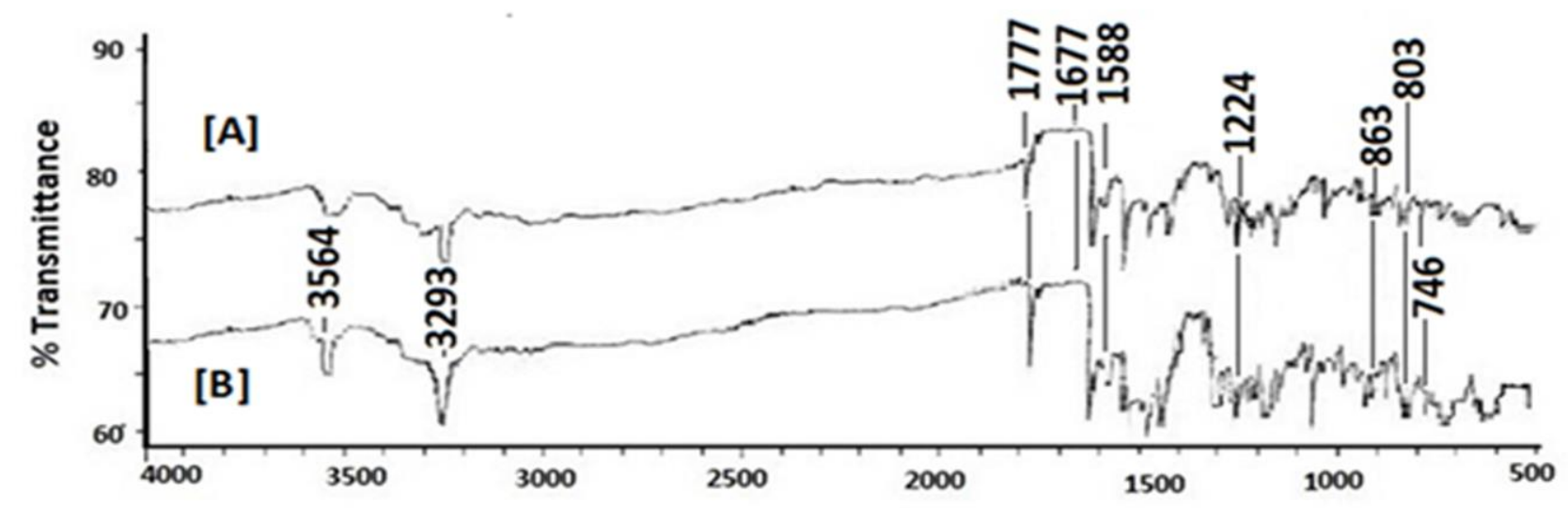

Figure 9: FTIR spectra of pure CFX (A) and processed nano formulation (CFX-4).

\section{Long term stability studies}

Samples stored at refrigerated $\left(4 \pm 2{ }^{\circ} \mathrm{C}\right)$ and room temperature $\left(25 \pm 3{ }^{\circ} \mathrm{C}\right)$ were characterized to evaluate particle size along with PDI. Nano formulation stored at both temperatures exhibited minor changes in particle size as well as PDI (Table 2). The increase in particle size and PDI was slightly smaller at refrigerated temperature compared to room temperature. It was noticed that increase in particle size corresponded to $15 \%$ at $25 \pm 3{ }^{\circ} \mathrm{C}$, whereas, increase at $4 \pm 2{ }^{\circ} \mathrm{C}$ was equivalent to $2 \%$ after 90 days of storage. $P$-values for particle size and PDI were reported as 0.043 
and 0.022 respectively, as confirmed through statistical analysis performed by two tailed $t$-test trial.

Table 2: Particle size and PDI of nano formulation (CFX-4) during stability studies.

\begin{tabular}{|c|c|c|c|c|}
\hline Day & $\begin{array}{c}\text { Size }(\mathrm{nm}) \\
4 \pm 2^{\circ} \mathrm{C}\end{array}$ & $\begin{array}{c}\text { Size }(\mathrm{nm}) \\
25 \pm 3^{\circ} \mathrm{C}\end{array}$ & $\begin{array}{c}\text { PDI } \\
4 \pm 2{ }^{\circ} \mathrm{C}\end{array}$ & $\begin{array}{c}\text { PDI } \\
25 \pm 3^{\circ} \mathrm{C}\end{array}$ \\
\hline $1^{\text {st }}$ & 206 & 206 & 0.271 & 0.271 \\
\hline $15^{\text {th }}$ & 207.2 & 216 & 0.272 & 0.372 \\
\hline $30^{\text {th }}$ & 208.8 & 219 & 0.280 & 0.411 \\
\hline $60^{\text {th }}$ & 209 & 227 & 0.291 & 0.45 \\
\hline $90^{\text {th }}$ & 210 & 238 & 0.315 & 0.522 \\
\hline Mean & 208.2 & 221.2 & 0.2858 & 0.4052 \\
\hline$S^{a}$ & 1.587451 & 12.02913 & 0.018185 & 0.093267 \\
\hline P-Value & \multicolumn{2}{|c|}{0.043} & \multicolumn{2}{|c|}{0.022} \\
\hline
\end{tabular}

SDa: Standard deviation.

\section{In-vitro dissolution study}

Drug release profile of nano formulations (CFX-1, CFX-2, CFX-3, CFX-4, and CFX-5) was studied for $12 \mathrm{hrs}$ in phosphate buffer solution ( $\mathrm{pH} 7.4)$. Collective percentage drug release from different nano-formulations CFX-1 to CFX-5 was observed as 98.16\%, 93.12\%, 86.33\%, 76.87\% and 64.79\% respectively (Figure 10). The obtained data was fitted into specialized kinetic models, with resultant $\mathrm{R}^{2}$ values between 0.946-0.995 (Table 3). The findings suggested that drug release followed zero order kinetics [32]. Whereas, 'n' value for korsmeyer-peppas model was found greater than 0.5 substantiating non-fickian diffusion for prepared nano formulations [33]. 


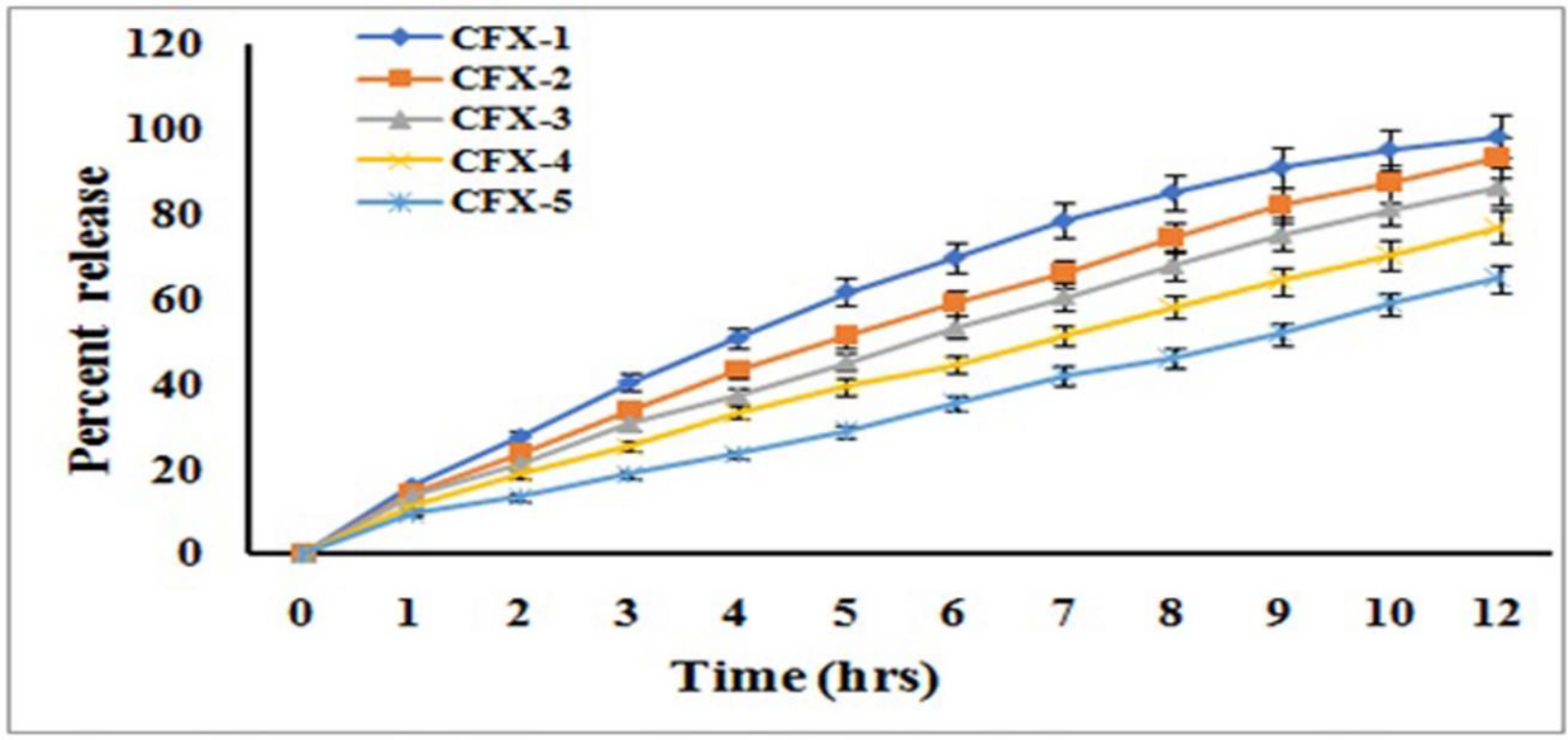

Figure 10: Drug release pattern of numerous CFX nano-formulations.

Table 3: $R^{2}$ values of different kinetic models for various CFX nano-formulations.

\begin{tabular}{|c|c|c|c|c|c|}
\hline \multirow{2}{*}{$\begin{array}{l}\text { Formulat } \\
\text {-ion }\end{array}$} & \multirow{2}{*}{$\begin{array}{c}\text { Zero } \\
\text { order } \\
\left(R^{2}\right)\end{array}$} & \multirow{2}{*}{$\begin{array}{c}\text { First } \\
\text { order } \\
\left(R^{2}\right)\end{array}$} & \multirow{2}{*}{$\begin{array}{c}\text { Higuchi } \\
\text { model } \\
\left(R^{2}\right)\end{array}$} & \multicolumn{2}{|c|}{ Korsmeyer-Peppas model } \\
\hline & & & & $\begin{array}{l}\text { Release exponent } \\
(\mathrm{n})\end{array}$ & $\left(R^{2}\right)$ \\
\hline CFX-1 & 0.946 & 0.943 & 0.973 & 0.766225 & 0.976 \\
\hline CFX-2 & 0.977 & 0.956 & 0.966 & 0.854534 & 0.959 \\
\hline CFX-3 & 0.982 & 0.975 & 0.960 & 0.877476 & 0.948 \\
\hline CFX-4 & 0.988 & 0.986 & 0.958 & 0.890169 & 0.945 \\
\hline CFX-5 & 0.995 & 0.984 & 0.932 & 0.988891 & 0.913 \\
\hline
\end{tabular}

\section{In-vivo studies}

Data of in-vivo study is shown as a function of drug plasma concentration versus time graph (Figure 11). Different pharmacokinetic findings are enlisted in Table 4. During HPLC analysis of plasma samples, it was observed that concentration of CFX was found profoundly higher for nano-suspension (CFX-4) compared to the marketed product. For nano formulation (CFX-4), and marketed product, maximum plasma 
concentration $\left(\mathrm{C}_{\max }\right)$ was $1.25 \pm 0.20 \mu \mathrm{g} / \mathrm{ml}$ and $0.667 \pm 0.13 \mu \mathrm{g} / \mathrm{ml}$ whereas, area under curve (AUC $0-24)$ was $135.21 \pm 0.004 \mu \mathrm{g} \cdot \mathrm{hr} \cdot \mathrm{ml}^{-1}$, and $41.79 \pm 0.031 \mu \mathrm{g} \cdot \mathrm{hr} \cdot \mathrm{ml}^{-1}$ in that order. These findings proposed 1.87-fold increase in $\mathrm{C}_{\max }$ and 3.23-fold increase in relative bioavailability of CFX nano suspension compared to the marketed product. This difference unveiled maximum absorption of CFX nano suspension and prepared dosage form in comparison to the marketed product.

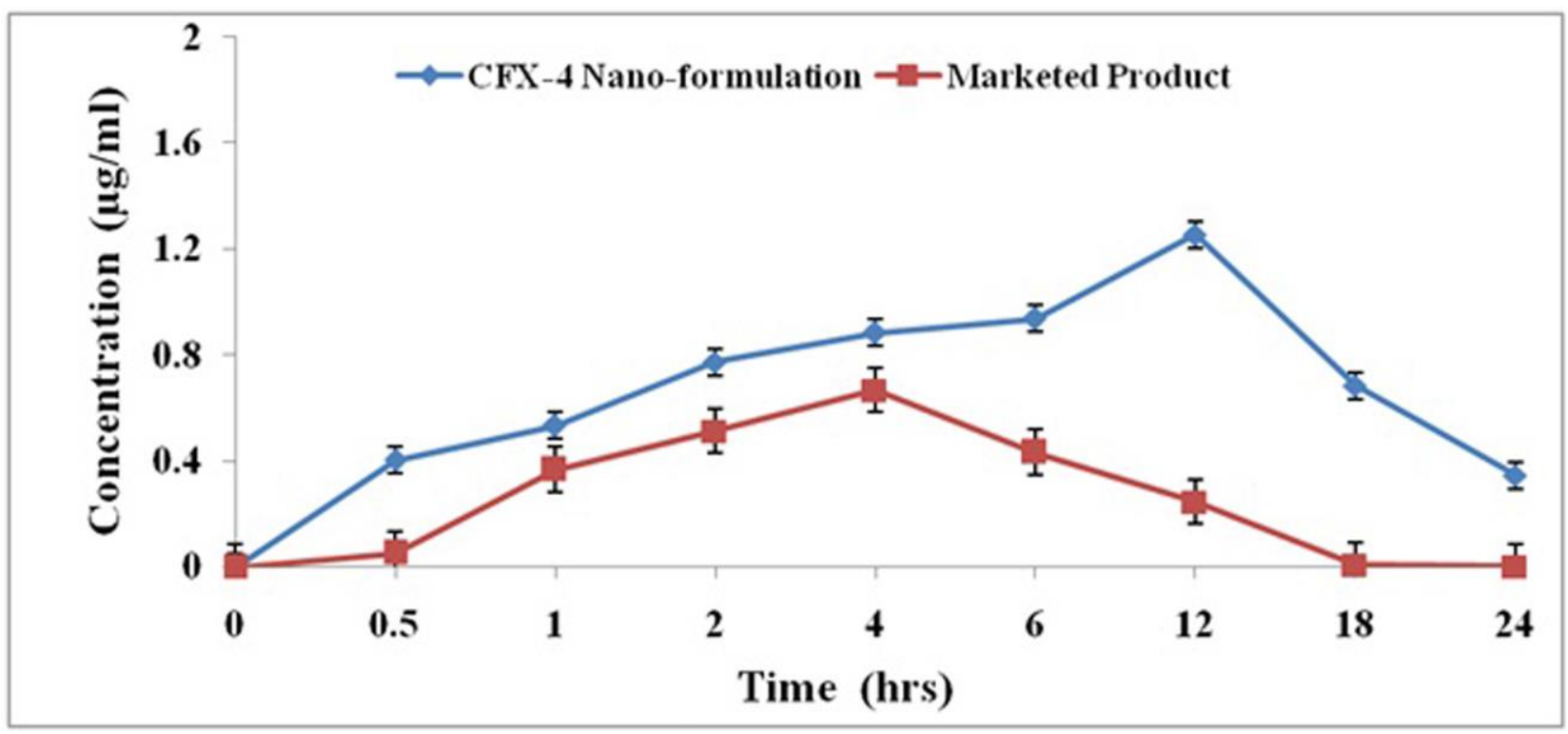

Figure 11: In-vivo drug release of CFX nano formulation and marketed product.

Table 4: In-vivo pharmacokinetics of CFX nano formulation and marketed product.

\begin{tabular}{|c|c|c|}
\hline Parameter & Marketed Product & $\begin{array}{l}\text { Nano-formulation (CFX- } \\
\text { 4) }\end{array}$ \\
\hline$C_{\max }$ & $0.667 \pm 0.13$ & $1.25 \pm 0.20$ \\
\hline$T_{\max }(\mathrm{h})$ & $4 \pm 0.2$ & $12 \pm 0.4$ \\
\hline AUC $(\mu \mathrm{g} / \mathrm{hr} / \mathrm{ml})$ & $41.79 \pm 0.031$ & $135.21 \pm 0.004$ \\
\hline $\begin{array}{l}\text { Relative Bioavailability } \\
\text { (Fr) }\end{array}$ & \multicolumn{2}{|c|}{3.23} \\
\hline
\end{tabular}




\section{Discussion}

In the present study, binary SLNs were fabricated using a drug carrier for oral administration of CFX. Unloaded binary SLNs prepared via HME technique, were optimized by changing various processing parameters. Optimized unloaded formulation (UBS-5) was selected for CFX loading (Table 1).

During optimization it was observed that alteration in surfactant concentration has a marked effect on particle size i.e. by increasing the concentration of tween-80 drastic decrease in particle size was observed (Table 1) [34]. Likewise, upon addition of cosurfactant supplementary particle size reduction was experienced. As, SLNs formulated with the combination of surfactant/co-surfactant presented smaller size particles and better physical stability [34, 35]. Similarly, escalating stirring time caused reduction in PDI, which is necessary for homogeneity of the dispersed system (Table 1) [36]. Optimized unloaded nano formulation (UBS-5) showed particle size $223.7 \pm 2.3 \mathrm{~nm}$ along with PDI $0.322 \pm 0.004$. Subsequent to drug loading further reduction in particle size was observed for CFX-4 to $206.6 \pm 2.3 \mathrm{~nm}$ with PDI $0.271 \pm 0.03$ (Figure 3). Size reduction following drug loading was observed because free lipid content was occupied by the drug in nano-particulate system [37]. Zeta potential was recorded as $-30.7 \pm 3.1 \mathrm{mV}$ for $\mathrm{CFX}-4$ nano formulation which imparted electrostatic stability to the system (Figure 4). Electrostatic stability of this system is due to the presence of negative charge on the surface of particles preventing particles aggregation $[38,39]$. Zeta potential from \pm 20 to \pm 50 is necessary to maintain stability of formulated nano suspension as well as avoids ostwald ripening and particle growth [38].

Evaluation of EE\% and DLC\% demonstrated that as the drug load was increased from $100 \mathrm{mg}$ to $300 \mathrm{mg}$, EE\% was decreased from $96 \%$ to $76 \%$ (Figure 5). This rapid 
fall in EE\% was owed to drug loading afar lipid's saturation limit [19]. Additionally, lipophilic drugs demonstrate utmost saturation within melted lipids; but upon cooling, the level of saturation reduces and extra amount tend to separate either into the external layer or outer solvent [40]. Optimized nano formulation (CFX-4) showed maximum EE\% (88.2 $\pm 2.3 \%)$ and DLC\% $(4.83 \pm 0.16 \%)$ confirming complete drug dissolution in the lipid blend, which is attributed to strong binding affinity of CFX for lipid mixture [41].

Analysis of SEM micrograph for optimized nano formulation (CFX-4) exposed almost identical, smooth and spherical shaped particles (Figure 6). Non spiky and blunt particles in the SEM micrograph were indicative of amorphous nature of nano particles. This amorphous nature of prepared nano formulation plays a key role in solubility and oral bioavailability enhancement [42].

DSC thermogram of unprocessed CFX, demonstrated sharp endothermic peak around $220^{\circ} \mathrm{C}$. Whereas, in case of processed nano formulation (CFX-4) diffused peak pattern was observed at $215{ }^{\circ} \mathrm{C}$ indicating particles size reduction, increased surface area and close contact between SA and CFX. All these factors confirmed conversion of CFX to less crystalline form facilitating enhanced drug solubilization (Figure 7) [43]. P-XRD diffractogram for unprocessed CFX revealed several sharp intense peaks. Whereas, for optimized nano formulation (CFX-4) decline in peak intensity was noticed confirming apparent reduction in crystallinity of CFX (Figure 8) [44]. Reduction in crystallinity predisposes the drug to attain greater amount of free energy, favoring effortless drug solubilization ultimately leading to enhanced oral bioavailability $[45,46]$.

FT-IR spectra of un-processed CFX and optimized nano formulation (CFX-4) revealed almost similar peak patterns confirming integrity of the functional groups present in the nano formulation. These observations suggested no significant 
interaction among CFX, lipid and other formulation ingredients (Figure 9). As no new complex amongst the components of formulation was formed thus, the prepared nano formulation could be processed further to achieve desirable improved oral bioavailability.

During stability studies, storage of samples at both temperatures showed in significant increase in size and PDI (Table 2). As compared to room temperature, refrigerated temperature was considered best for storage of CFX nano formulation [43]. As at room temperature $\left(25 \pm 3{ }^{\circ} \mathrm{C}\right)$ rapid increase in particle size was observed in the initial phase following stabilization for the remaining phase. The initial particle growth is attributed to the higher extent of free energy, acquired by amorphous solids at room temperature influencing their physical and chemical stability [45, 46]. Additionally this typical growth pattern might be attributed to the transition of solid lipid to $\beta$-polymorphic form, which is quite stable to the effects of light and temperature [47].

In-vitro drug release kinetics exposed initial burst release for all the prepared nano formulations. Also, it was observed that increase in drug payload resulted in sustained drug release pattern (Figure 10) [19]. Sustained release pattern could possibly delay drug clearance, resulting in higher CFX blood level [48]. Drug release data was fitted well in to different kinetic-models which revealed that release of drug followed zero order kinetics (Table 3). Whereas, in case of korsmeyer peppas model the value obtained for release exponent ' $n$ ' was more than 0.5 , authenticating nonfickian diffusion (anomalous transport) for all the prepared nano formulations [49]. During in-vivo pharmacokinetic studies significant increase was observed in relative bioavailability of nano suspension (CFX-4) compared to the marketed product (Table 4). Major increase in oral bioavailability can be credited to smaller particle size, resulting in large surface area [50]. These factors facilitates adherence of drug 
particles to intestinal epithelial cells, resulting in greater absorption [51]. Thus, binary SLNs can be used as an advanced drug carrier system to facilitate delivery of hydrophobic drugs (BCS-II \& BCS-IV) to boost up their oral bioavailability along with provision of sustained drug release characteristics.

\section{Conclusion}

Binary SLNs prepared from the blend of solid and liquid lipid offered advanced physicochemical properties and long term storage stability. In-vitro studies exposed sustained release of CFX, which is directly proportional to drug payload. Drug release from different nano formulations pursued zero order kinetics and was diffusion controlled. Pharmacokinetic findings demonstrated that CFX binary SLNs offered desired improvement in oral bioavailability as compared to marketed product. Hence, it is concluded that CFX loaded binary SLNs; productively fabricated through effortless and reproducible technique (HME) could be effectively utilized as an alternative drug delivery system for hydrophobic drugs and may possibly be upgraded for large scale production.

\section{Acknowledgments}

The authors would aim to acknowledge Higher Education Commisssion of Pakistan for sponsoring this research throuh NRPU project No. NO. NRPU-I/10004, Alliance Pharmaceuticals (Pvt) Ltd, Peshawar-Pakistan for provision of cefixime as a munificent gift, Lahore University of Management Sciences (LUMS) for providing characterization facilities, University of Agriculture Peshawar, (Department of poultry sciences) for conducting in-vivo studies, Aries pharmaceuticals (pvt) Ltd Peshawar for HPLC facility. 


\section{References}

1. Lipinski, C. Am. Pharm. Rev. 2002, 5, 82-85.

2. Maraie, N. K.; T Alhamdany, A.; Radhi, A. A. Asian. J. Pharm.Clin.Res. 2017, 10, 394-401.

3. Paradkar, A.; Ambike, A. A.; Jadhav, B. K.; Mahadik, K. Int. j. pharm. 2004, $271,281-286$.

4. Han, H.-K.; Choi, H.-K. Eur. J. Pharm. Biopharm. 2007, 65, 99-103.

5. Jun, S. W.; Kim, M.-S.; Kim, J.-S.; Park, H. J.; Lee, S.; Woo, J.-S.; Hwang, S.J. Eur. J. Pharm. Biopharm. 2007, 66, 413-421.

6. De Jong, W. H.; Borm, P. J. Int. J. nanomed. 2008, 3, 133-149.

7. Mehnert, W.; Mäder, K. Adv. drug deliv. rev. 2012, 64, 83-101.

8. Rabinow, B. E. Nat. rev. Drug. discov. 2004, 3, 785-796.

9. Valeh-e-Sheyda, P.; Rahimi, M.; Adibi, H.; Razmjou, Z.; Ghasempour, H. Chem. Eng. Process: Process Intensification. 2015, 91, 78-88.

10. Shah, R.; Eldridge, D.; Palombo, E.; Harding, I. J. Phys. Sci. 2014, 25, 59-75

11. Esposito, E.; Sguizzato, M.; Drechsler, M.; Mariani, P.; Carducci, F.; Nastruzzi, C.; Valacchi, G.; Cortesi, R. Beilstein. J. Nanotechnol. 2019, 10, 1789-1801.

12. zur Mühlen, A.; Schwarz, C.; Mehnert, W. Eur. j. pharm. biopharm. 1998, 45, 149-155.

13. Sweetman, S. C. Martindale: The Complete Drug Reference; Pharmaceutical Press, London, 2005.

14. Paul, Y.; Kumar, M.; Singh, B. Int. J. Drug. Dev. Res. 2011, 3, 148-161.

15. Moffat, A. C.; Osselton, M. D.; Widdop, B.; Watts, J. Clarke's analysis of drugs and poisons, Vol. 3: Pharmaceutical press London, 2011. 
16. Khan, F. A.; Zahoor, M.; Islam, N. U.; Hameed, R. J. Nanomater. 2016, 2016, 6909085.

17. Loftsson, T.; Muellertz, A.; Siepmann, J. Int. j. pharm. 2013, 453, 1-2.

18. Garud, A.; Singh, D.; Garud, N. Int. Curr. Pharm. J. 2012, 1, 384-393.

19. Rehman, M.; Asadullah Madni, A. I.; Khan, W. S.; Khan, M. I.; Mahmood, M. A.; Ashfaq, M.; Bajwa, S. Z.; Shakir, I. Int. j. nanomed. 2015, 10, 2805-2814.

20. Dey, S.; Pradhan, P. K.; Upadhayay, U.; Shah, S.; Goswami, K. J. Pharm. Res. 2012, 5, 5419-5422.

21. Kim, B.-D.; Na, K.; Choi, H.-K. Eur. j. pharm. sci. 2005, 24, 199-205.

22. Abdelwahed, W.; Degobert, G.; Stainmesse, S.; Fessi, H. Adv. drug deliv. rev. 2006, 58, 1688-1713.

23. Shafique, M.; Khan, M. A.; Khan, W. S.; Ahmad, W.; Khan, S. J. Nanomater. 2017, 2017, 10 pages (ID-7357150).

24. Sirisolla, J.; Ramanamurthy, K. j. pharm. sci. 2015, 77, 321-327.

25. Hou, D.; Xie, C.; Huang, K.; Zhu, C. Biomater. 2003, 24, 1781-1785.

26. Chauhan, H.; Mohapatra, S.; Munt, D. J.; Chandratre, S.; Dash, A. AAPS PharmSciTech. 2016, 17, 640-651.

27. Bhardwaj, U.; Burgess, D. J. Int. J. Pharm. 2010, 388, 287-294.

28. Gomathi, T.; Govindarajan, C.; Hr, M. H. R.; Sudha, P.; Imran, P. M.; Venkatesan, J.; Kim, S.-K. Int. j. pharm. 2014, 468, 214-222.

29. Roohullah, Z. I.; Nasir, F.; Akhlaq, M.; Sadozai, S.; Zada, A.; Khan, A. MiddleEast. J. Sci. Res. 2013, 15, 1368-74.

30. Vasam, M.; Ponugoti, R. S. R. World. J. Pharm. Pharm. Sci. 2017, 7, 14761488.

31. Kelly, T. Clarke's analysis of drugs and poisons: Taylor \& Francis, 2012.

32. Costa, P.; Lobo, J. M. S. Eur. J. pharm. sci. 2001, 13, 123-133. 
33. Barzegar-Jalali, M.; Adibkia, K.; Valizadeh, H.; Shadbad, M. R. S.; Nokhodchi, A.; Omidi, Y.; Mohammadi, G.; Nezhadi, S. H.; Hasan, M. J. Pharm. Pharm. Sci. 2008, 11, 167-177.

34. Kovacevic, A.; Savic, S.; Vuleta, G.; Müller, R.; Keck, C. Int. J. pharm. 2011, 406, 163-172.

35. Padhye, S.; Nagarsenker, M. S. Indian. J. pharm. sci. 2013, 75, 591-598.

36. Baharifar, H.; Tavoosidana, G.; Karimi, R.; Bidgoli, S. A.; Ghanbari, H.; Faramarzi, M. A.; Amani, A. J. Nanosci. Nanotechnol. 2015, 15, 10127-10133.

37. Rehman, M. U.; Khan, M. A.; Khan, W. S.; Shafique, M.; Khan, M. Artif cells. nanomed. biotechnol. 2017, 1-9.

38. Liu, J.; Hu, W.; Chen, H.; Ni, Q.; Xu, H.; Yang, X. Int. j. pharm. 2007, 328, 191195.

39. Schwarz, C. J. microencapsul. 1999, 16, 205-213.

40. MuÈller, R. H.; MaÈder, K.; Gohla, S. S. Eur. J. Pharm. Biopharm. 2000, 50, $161-177$.

41. Liu, Y.; Pan, J.; Feng, S.-S. Int. j. pharm. 2010, 395, 243-250.

42. Vasconcelos, T.; Sarmento, B.; Costa, P. Drug. discov. today. 2007, 12, 10681075.

43. Elmowafy, M.; Ibrahim, H. M.; Ahmed, M. A.; Shalaby, K.; Salama, A.; Hefesha, H. Drug. deliv. 2017, 24, 932-941.

44. Khan, S.; Matas, M. d.; Zhang, J.; Anwar, J. Cryst. Growth. Des. 2013, 13, 2766-2777.

45. Khawam, A.; Flanagan, D. R. J. pharm. sci. 2006, 95, 472-498.

46. Hancock, B. C.; Zografi, G. J. pharm. sci. 1997, 86, 1-12.

47. Oehlke, K.; Behsnilian, D.; Mayer-Miebach, E.; Weidler, P. G.; Greiner, R. PloS one. 2017, 12, e0171662. 
48. Soma, D.; Attari, Z.; Reddy, M. S.; Damodaram, A.; Koteshwara, K. B. G. Braz. J. Pharm. Sci. 2017, 53, e15012.

49. Sadiq, A. A.; Rassol, A. A. Int .J. Pharm. Pharm. Sci. 2014, 6, 55-67.

50. de Dicastillo, C. L.; Patiño, C.; Galotto, M. J.; Vásquez-Martínez, Y.; Torrent, C.; Alburquenque, D.; Pereira, A.; Escrig, J. Beilstein. J. Nanotechnol. 2019, $10,1716-1725$.

51. Xia, S.; Xu, S.; Zhang, X. J. agric. food. chem.2006, 54, 6358-6366. 